\title{
Thermogravimetric Analysis Studies
}

\author{
Greg Gdowski
}

August 25, 1995

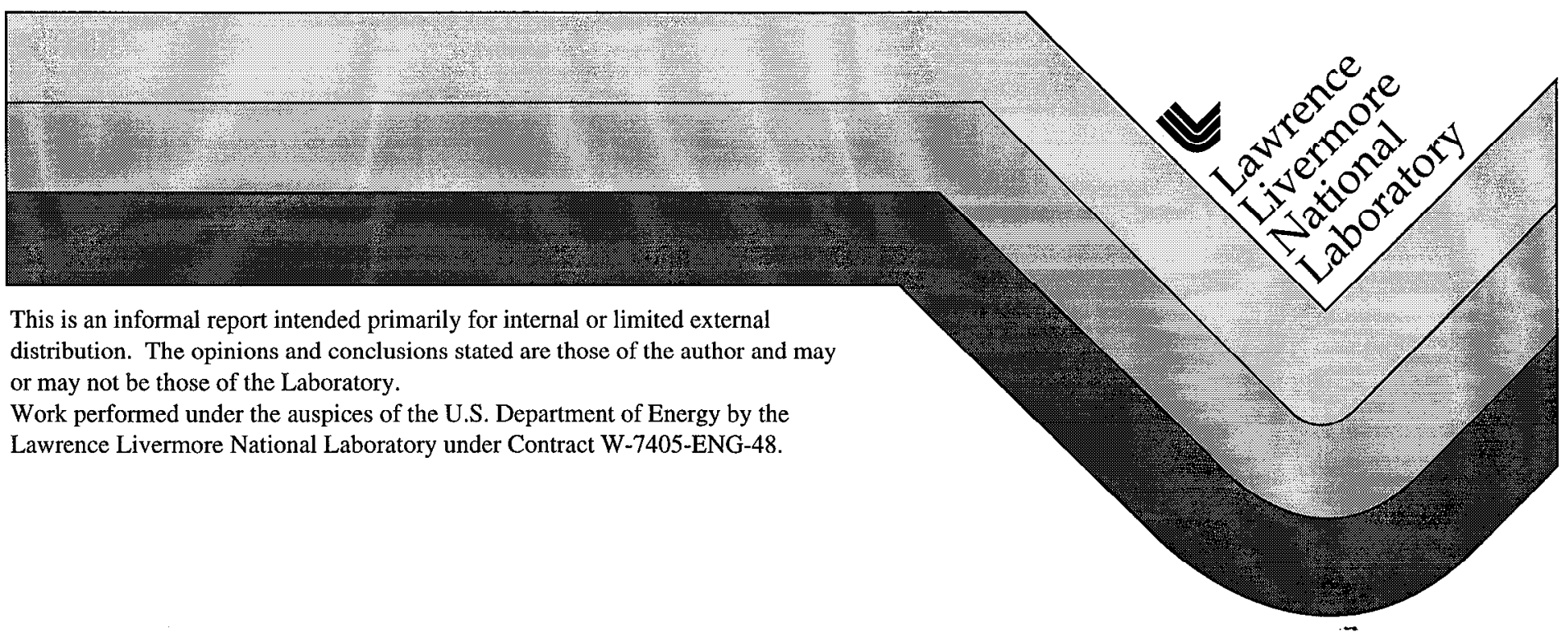




\section{DISCLAIMER}

This document was prepared as an account of work sponsored by an agency of the United States Government. Neither the United States Government nor the University of California nor any of their employees, makes any warranty, express or implied, or assumes any legal liability or responsibility for the accuracy, completeness, or usefulness of any information, apparatus, product, or process disclosed, or represents that its use would not infringe privately owned rights. Reference herein to any specific commercial product, process, or service by trade name, trademark, manufacturer, or otherwise, does not necessarily constitute or imply its endorsement, recommendation, or favoring by the United States Government or the University of California. The views and opinions of authors expressed herein do not necessarily state or reflect those of the United States Government or the University of California, and shall not be used for advertising or product endorsement purposes.

This report has been reproduced directly from the best available copy.

Available to DOE and DOE contractors from the

Office of Scientific and Technical Information

P.O. Box 62, Oak Ridge, TN 37831

Prices available from (423) 576-8401

Available to the public from the

National Technical Information Service

U.S. Department of Commerce

5285 Port Royal Rd.,

Springfield, VA 22161 


\section{University of California \\ Lawrence Livermore \\ National Laboratory \\ YUCCA MOUNTAIN PROJECT \\ Activity Plan}

Subject:

Thermogravimetric Analysis Studies
No.: $\quad E-20-47$

Revision: $\quad 0$

Change Notice: N/A

Page: 1 of 20

Training Required: Yes $\mathrm{No} \square$

Comments:

Training as specified in Training section of this Activity Plan.

REVISION HISTORY

Rev. No.

CN No.

Effective Date

Description of Revision/CN

0

$8 / 25 / 95$

Initial issue

Gregory E. Gdowski

AUTHOR:

$8 / 25 / 95 \quad$ Initial issue

APPROVALS:
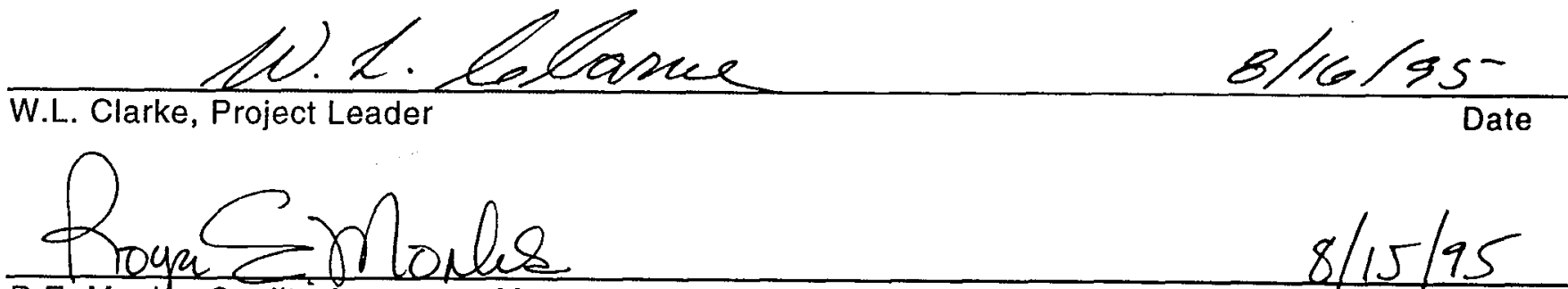

R.E. Monks, Quality Assurance Manager
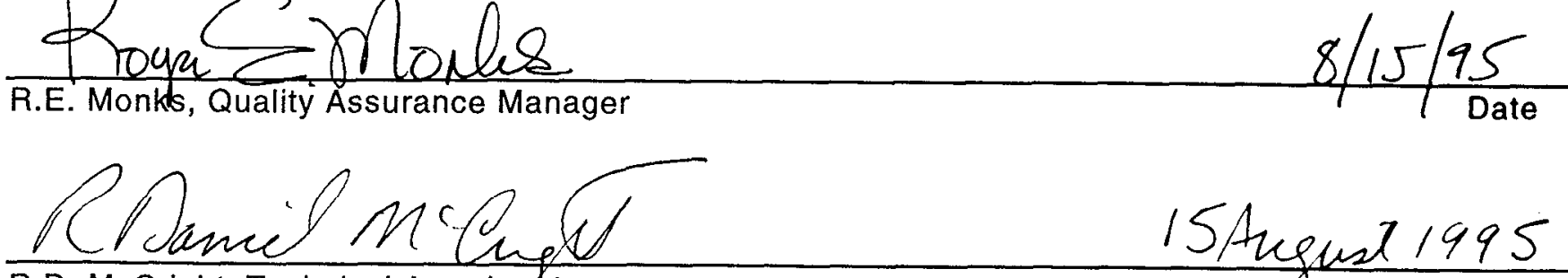

R.D. McGright, Technical Area Lezder

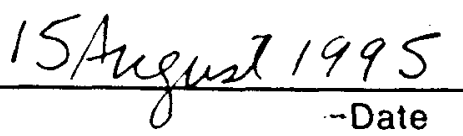




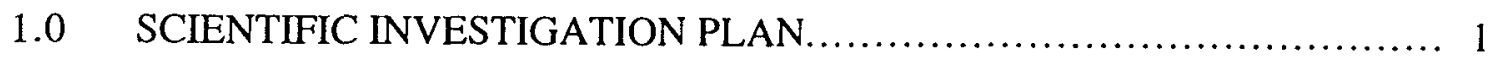

1.1 Activity Identity ............................................

$1.2 \quad$ Responsibilities .................................................... 1

2.0 SCOPE, PURPOSE, AND OBJECTIVES ............................... 2

$3.0 \quad$ ACTIVITY DESCRIPTION ......................................... 3

3.1 Technical and Readiness Reviews.................................. 5

$3.2 \quad$ Hold points ....................................................... 5

$3.3 \quad$ Equipment .......................................................... 5

$3.4 \quad$ Materials ............................................................ 7

3.5 Special Environmental Conditions.................................. 8

3.6 Special Training/Qualification Requirements........................... 9

3.7 Quality Assurance Program ................................... 9

$3.8 \quad$ Activity Closeout .................................................... 9

4.0 PRECISION AND ACCURACY ........................................ 9

4.1 Calibration Requirements........................................... 10

4.2 Conditions which may adversely affect results ........................ 10

4.3 Sources of uncertainty and error to be controlled and measured..........10

$4.4 \quad$ Standards ........................................................... 11

$5.0 \quad$ IN-PROCESS DOCUMENTATION ....................................... 11

5.1 Data Recording and Data Reduction...................................11

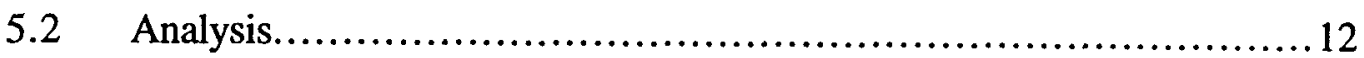

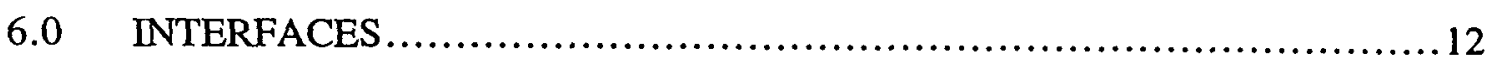

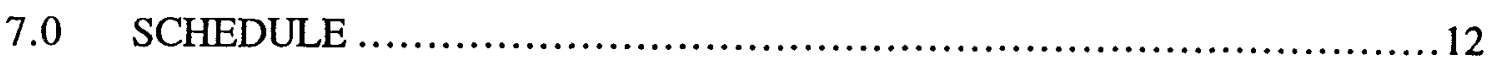

8.0 TECHNICAL IMPLEMENTING PROCEDURES............................ 13

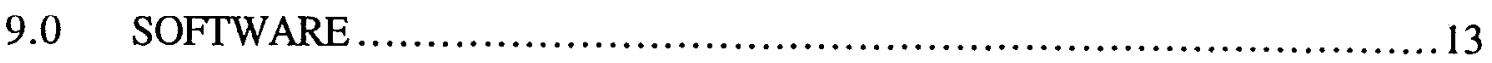

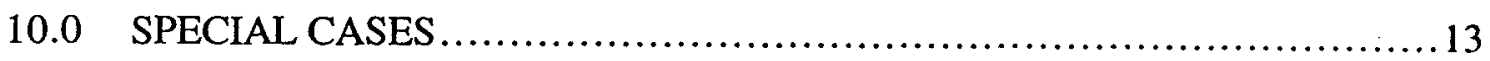

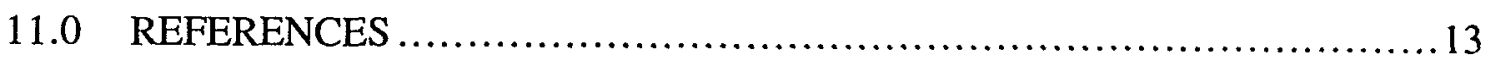

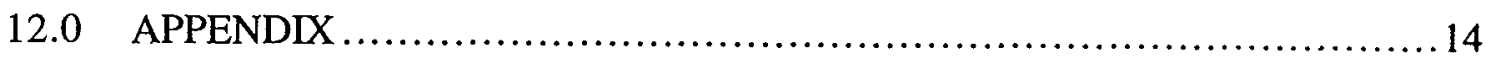

Table 1. Compositions of Candidate Container Materials........................... 15

Figure 1. Thermogravimetric Analyzer Apparatus .................................17 


\subsection{SCIENTIFIC INVESTIGATION PLAN}

This activity plan is prepared in accordance with Lawrence Livermore National Laboratory (LLNL) Yucca Mountain Project procedure 033-YMP-QP 3.0, "Scientific Investigation Control." This plan is written for Activity E-20-47, "Thermogravimetric Analysis Studies," which is part of the Scientific Investigation Plan (SIP) '"Metal Barrier Selection and Testing" (SIP-CM-01, WBS \#1.2.2.5.1).

1.1 Activity Identity

This activity is entitled "Thermogravimetric Analysis Studies" and has been assigned the activity number E-20-47 and is part of the Short Term Abiotic Laboratory Corrosion Testing described in the SIP "Metal Barricr Sclection and Testing." This activity will be QA graded in accordance with procedure 033-YMPQP 2.8, "Quality Assurance Grading," and it is expected that it will be graded as non-quality affecting.

\subsection{Responsibilities}

Key personnel responsible for performing the work in this activity are:

Technical Area Leader:

Container Materials, Modeling, and Testing

Task Leader:

Metal Barrier Selection and Testing

Principal Investigator:
Dr. R.D. McCright

Dr. E.N.C. Dalder

Dr. G.E. Gdowski 
Independent of thermal loading scenarios, the waste packages at the proposed repository at Yucca Mountain, Nevada will be exposed to environmental conditions of temperatures below $100^{\circ} \mathrm{C}$ with a range of possible relative humidities. Under high relative humidities, the formation of thin water films on the metal surfaces will occur. Previous work at ambient conditions has shown that on susceptible metals, the water-film-covered metal has an enhanced corrosion rate relative to the dry oxidation of the metal. The transition relative humidity where oxidation changes from "dry oxidation" to "aqueous electrochemical corrosion" is called the "critical relative humidity". Determination of this transition is important in estimating the performance of the candidate materials (especially corrosion allowance materials), because of the marked increase in degradation rate above the critical relative humidity, typically $10-10^{2}$ times

This activity is concerned with short term measurements of corrosion and oxidation rates using a high sensitivity microbalance. The experimental work will determine the critical humidity level for candidate metals under a variety of conditions. From the literature, the critical humidity level typically are around $70 \%$ relative humidity, but this level is affected by the metal, gas composition, temperature, and the presence of contaminants on the surface, particularly contaminants that are deliquescent. A series of experiments will bracket a range of humidity, temperature, metal alloy, and surface condition.

The results of this study will be used to assist:

1) in determining the test parameters for the activity "Long Term Corrosion / Oxidation Studies under Controlled Humidity Conditions" (E-20-59),

2) in the activity "Recommendation of Container Materials (E-20-91),

3) in the Waste Package Performance Assessment Activities (SIP-PA-2),

4) in the modeling activities "Low Temperature Oxidation Model Development" (E-20-75) and "General Aqueous Corrosion Model Development" (E-20-76), and

5) in the Near-Field Environment and Waste Package / Repository Design effort, (many of the technical issues associated with the thermal output and arrangement of waste packages in the repository greatly influence the humidity levels around the container surface and their result on container performance). 


\subsection{ACTIVITY DESCRIPTION}

This activity will investigate the effect of water vapor content (relative humidity) of air on the oxidation / corrosion of candidate waste package metals. In addition to relative humidity, other factors, such as surface impurities (hygroscopic species), gas composition, temperature, and surface condition, influence metal corrosion/oxidation rates. These other parameters will also be investigated. In particular, the critical humidity as function of the test parameters will be obtained. In addition, kinetic and mechanistic information on the "dry oxidation" and "aqueous electrochemical corrosion" processes will be obtained.

The focus of this activity will be on the environmental conditions where aqueous electrochemical corrosion can occur, that is, at temperatures below $100^{\circ} \mathrm{C}$ and at high relative humidities. The practical lower temperature limit is $35-40^{\circ} \mathrm{C}$ (temperature control bath lower limit) and upper relative humidity is about $90-95 \%$, since water condensation in the test vessel becomes a problem at very high relative humidities. All tests will be performed at atmospheric pressure.

This activity will use a modified CAHN TG-131 thermogravimetric analyzer (TGA) to measure specimen weight changes due to humidified air (0 to $95 \%$ relative humidity) interactions with the metallic test specimens. The CAHN TGA has been modified in order to achieve stable temperatures in the test vessel reaction zone and small temperature differences across the reaction zone. In addition, a water vapor delivery system has been added to supply the test vessel with controlled relative humidity air. (See Section 3.3 "Equipment" for further details.)

This activity will also use surface analytical techniques to investigate the surface composition and structure of the oxidized metal in order to investigate variations due to different test conditions. The surface analytical techniques will reveal complementary information on the mechanisms of oxidation and also on stability of the oxide structure. Techniques that may be employed include x-ray diffraction, microprobe analysis, Auger electron spectroscopy, $\mathrm{x}$-ray photoelectron spectroscopy, infrared spectroscopy, and electron microscopy.

Some simple surface wetting tests will also be employed to characterize the oxide layers formed. In brief, porous and cracked oxide layers are wetted quite readily by water, while, in contrast, a continuous and dense oxide layers are not wetted significantly by water. The extent of the wetting can be quantified by relative easy surface tension measurements. 
Three classes of metallic alloys are to be assessed: corrosion resistant, intermediate corrosion resistant, and corrosion allowance. The corrosion resistant materials are the high nickel alloys, Alloys C-22, C-4, G-3, and 825, and the dilute titanium alloys, Ti-Grades 12 and 16. The intermediate corrosion resistant materials are Monel 400 and $\mathrm{Cu}-30 \% \mathrm{Ni}$. The corrosion allowance materials are low alloy and carbon steels: 1020 carbon steel, cast steel, and 2.25\%Cr-1\%Mo steel. (See Section 3.4 "Materials" for further details.)

The initial focus of this activity will be on the corrosion allowance and intermediate corrosion resistant materials. These are the materials that are expected to be the most susceptible to the thin film aqueous electrochemical corrosion.

Two types of tests are initially planned. The first type of testing will determine critical relative humidity. The specimen will initially be held at an elevated temperature, and the reactant gas with a fixed vapor pressure of water will then be introduced to the test vessel. The specimen temperature will then be lowered at a fixed schedule. The weight change of the specimen as a function of temperature will indicate the temperature at which water films form on the specimen. The relative humidity will be measured simultaneously. Several tests will be run with various amounts of water vapor in the reactant air. From these tests, a map of the metal susceptibility to aqueous electrochemical corrosion as a function of temperature and relative humidity will be obtained. In other words the critical relative humidity as a function of temperature will be obtained for a specific set of test conditions.

Metal susceptibility to thin film aqueous corrosion will also be investigated as a function of other parameters, such as surface condition and surface impurities. Maps of metal susceptibility to aqueous electrochemical corrosion as a function of temperature and relative humidity will then be obtained for these other parameters. All the materials tested and the test conditions will be detailed in the scientific notebook.

In the second type of test, the metal specimen is held at fixed test parameters (temperature and relative humidity) for the duration of the test. The specimen's weight gain is recorded as a function of time, and after testing, the oxide layer of the specimen is characterized for structure and composition. From these tests information on the kinetics and mechanisms of the oxidation / corrosion reaction under fixed conditions will be obtained. The surface structural and compositional analysis will give indications of the "protectiveness" of the oxide layer formed. 


\subsection{Technical and Readiness Reviews}

Because this activity is not quality affecting, neither Technical nor Readiness

Reviews are planned to be performed; however, the following procedures will be complied with:

1. Measurement and test equipment (M\&TE) are properly calibrated as specified in Procedure 033-YMP-QP-12.0, "Control of Measuring \& Test Equipment".

2. Test specimens will be procured as specified in Procedure 033-YMPQP-4.0, "Procurement Document Control", and controlled as specified in Procedure 033-YMP-QP-8.0, "Identification and Control of Items, Samples, and Data".

3. Collected data will be controlled as specified in Procedure 033-YMPQP-8.0, "Identification and Contról of Items, Samples, and Data".

4. Scientific notebooks will be maintained as specified in Procedure 033YMP-QP-3.4, "Scientific Notebooks".

\subsection{Hold points}

The operation of the test facility will be monitored on a continuous basis by the Principal Investigator to insure that the work is proceeding according to plan. If significant unanticipated problems arise, the Principal Investigator will inform the Task Leader. A joint decision will be made about the future course of action.

The progress of the test will be reported to the Task Leader in monthly reports. If changes in project scope require that experimental work change direction, it is the responsibility of the Task Leader to communicate this to the Principal Investigator in writing.

In addition to the monthly progress reports, a yearly revicw of the progress of the activity is planned to ensure that the activity is proceeding according to the plan, that Scientific Notebooks are being used in accordance with Procedure 033-YMP-QP 3.4, "Scientific Notebooks," and that the activity records are properly maintained.

\subsection{Equipment}

The equipment used to perform the thermogravimetric analysis studies include:

Thermogravimetric analyzer (TGA); ATI/Mattson CAHN TG-131 
Personal computer (PC); Dell PC, 486 microprocessor, $33 \mathrm{MHz}, 4$ Megabyte RAM

Relative Humidity / Temperature (RTD) Sensor; HYCAL Model CT-890-AN

Data acquisition device; FLUKE Model Hydra Data Bucket

Mass flow controller; Unit Instruments Model UFC-1100A

Readout power supply; Unit Instruments Model URS -100

Double walled cylinder assembly; Thermal Interactions, Inc.

High Temperature Bath Fluid Recirculator; Neslab Model Exacal Ex250HT

Vapor Delivery System; MKS Model 25B

A schematic of the thermogravimetric analysis apparatus and support hardware is shown in Fig. 1.

The specimen weight changes are monitored by the microbalance of the TGA and recorded by the PC using ATI/Mattson developed Setup and Analysis (S\&A) software Version 1.2B. Air flow is controlled by the mass flow controller and programmable readout power supply while the $S \& A$ program supplies the process parameters to the programmable power supply.

The reaction vessel is a double-walled cylinder assembly. The temperature of the vessel is controlled by the transfer of heat from silicone oil flowing through the enclosed outer chamber. (The silicone oil is externally heated by the programmable heat bath.) The test specimen is located in the inner chamber and is surrounded by glass cylinder. The reactant air enters at the top of the inner chamber, travels down between the heated outer chamber and the glass cylinder. At the bottom of the inner chamber, the reactant gas then flows up past the test specimen, and finally the reactant gas exits out the top of the inner chamber. The reactant gas is heated before entering the test vessel, and its temperature is further controlled by its thermal contact with the heated outer chamber. Using this arrangement, the center line temperature of the test specimen is controlled to within $\pm 0.5^{\circ} \mathrm{C}$, and the temperature variation from top-to-bottom of a test specimen is less than $1^{\circ} \mathrm{C}$.

This reaction vessel configuration gives much better temperature control than that which was given by the original equipment supplied with the TGA. In the original TGA apparatus configuration, a single cylinder reaction vessel was heated by a resistance furnace. The test specimen center line temperature control was $\pm 2^{\circ} \mathrm{C}$ and temperature variation from top-to-bottom of a $5 \mathrm{~cm}$ test specimen was 15 to $20^{\circ} \mathrm{C}$. 
The test vessel also has an entry port in the bottom for a combined relative humidity / temperature sensor. The output from this sensor is collected by the Fluke Data Bucket as a function of time.

The data from the Fluke Data Bucket and the TGA control software are combined and stored in a spreadsheet program (e.g., Microsoft Excel or equivalent) for analysis and plotting.

At present, the air that is introduced into the test vessel is humidified with water by flowing air through a reservoir of water held at an elevated temperature. The unit is adequate for humidified air at temperatures up to $60^{\circ} \mathrm{C}$. Above that temperature the amount of water taken up by the air is inadequate to obtain high relative humidities in the test vessel. An alternate means of obtaining the high relative humidities is being implemented.

The alternate vapor delivery system, which consists of a metering pump, a vaporizer, and an electronic control unit, will be used to deliver precise amounts of water vapor to the test vessel in order to achieve high relative humidities at elevated temperatures. Briefly, the metering pump delivers very small and well defined amount of water to the vaporizer, where the water is vaporized and mixed with a carrier gas (air) and transported to the test vessel. For practical purposes, the flow of water from the metering pump is constant, and assuming a constant air flow is maintained, a stable relative humidity is obtained.

A reference specimen made of platinum and of similar geometry is placed in the tare vessel, and is subject to the same changes to environmental conditions. This minimizes changes to weight measurements that may be due to changes in air density in the reaction vessel. No measurement of humidity or temperature is taken in the tare vessel.

\subsection{Materials}

The candidate materials to be tested in this activity will primarily be those that are expected to be susceptible to enhance corrosion in high humidity air. These candidate materials are the low-alloy and carbon steels, and copper-nickel alloys. Some of the more corrosion resistant nickel-base and titanium-base candidate 
materials will also be tested. However, these materials are not expected to be susceptible to enhanced corrosion in high humidity air, and therefore, only limited testing is expected. The candidate materials are listed in the next paragraph.

All the materials to be tested in this activity are commercially available metal alloys. For the Metal Barrier Selection and Testing Task purposes, these materials have been classified in three groups based on their corrosion properties: "corrosion resistant", "intermediate corrosion resistant", and "corrosion allowance". The "corrosion resistant" materials are the high nickel alloys, Alloys C-22, C-4, G-3, and 825 , and the dilute titanium alloys, Ti-Grades 12 and 16 . The "intermediate corrosion resistant" materials are Monel 400 and $\mathrm{Cu}-30 \% \mathrm{Ni}$. The "corrosion allowance" materials are low alloy and carbon steels: 1020 carbon steel, cast steel, and $2.25 \% \mathrm{Cr}-1 \% \mathrm{Mo}$ steel. Table 1 contains the common names of the alloys, their Unified Numbering System identification number, and typical compositions.

The materials to be tested in this activity are structural materials that have been commercially used for at least 10 years, except for the newly developed Ti-Grade 16. However, Ti-Grade 16 is a dilute titanium alloy $(0.05 \mathrm{wt} . \% \mathrm{Pd})$ and is expected to have corrosion properties similar to the higher Pd content Ti-Grade 7 ( $0.2 \mathrm{wt} . \% \mathrm{Pd}$ ) under most conditions, but at much less cost. Mcchanical properties of Ti-Grade 16 are expected to be similar to commercial purity titanium (Ti-Grade 2).

Test specimens will be purchased commercial grade. The scientific notebook will contain the information on each metal alloy heat number, composition, and metallurgical condition. Otherwise the scientific notebook will reference the location of such information.

\subsection{Special Environmental Conditions}

The tests will be performed in purified air and in purified air with controlled amounts of $\mathrm{CO}_{2}$. Relative humidities will be controlled from 0 to $95 \%$. All testing will be performed at near atmospheric pressure. 
3.6 Special Training/Qualification Requirements

Qualifications of the Principal Investigator(s) and technicians are specified by the Task Leader in accordance with 033-YMP-QP 2.10 "Qualification of Personnel". A Principal Investigator shall have at least a B.S. degree in corrosion engineering, chemical engineering, electrochemical engineering, materials science, metallurgical engineering or equivalent. Technicians shall have experience in electrochemical or corrosion instrumentation and techniques. Only personnel trained to appropriate quality procedures and any other procedures of the Yucca Mountain Site Characterization Project will be allowed to participate in this activity.

\subsection{Quality Assurance Program}

The activity will comply with all procedures prescribed in the QA Grading performed in accordance with procedure 033-YMP-QP 2.8, "Quality Assurance Grading." The activity will be monitored for compliance through surveillances.

\subsection{Activity Closeout}

The final product of this activity will be a LLNL UCID report documenting all results. Supporting documentation such as scientific notebooks and technical review comments will be retained by the responsible individual until the document package is transferred to the LLNL/YMP Local Records Center at the conclusion of the activity. QA records will be transmitted as described in Procedure 033-YMPQP 17.0, "Quality Assurance Records."

\subsection{PRECISION AND ACCURACY}

There are two categories of measurement and analysis for this activity: the test parameters and the post-test analysis. During testing the parameters, specimen weight change, relative humidity, temperature, time, and air flow rates need to be controlled and/or monitored. The TGA apparatus measures weight changes to within $20 \mu$ grams. Temperature will be measured to within $\pm 0.5^{\circ} \mathrm{C}$. Relative humidity will be measured to with $\pm 5 \%$. TIPs that 
describe the calibration procedures for the monitoring devices are listed in "Technical Implementing Procedures" (Section 8.0).

Post-test analysis test specimen will include a characterization of the surface oxidation layer. Analysis devices could include, but are not limited to x-ray diffraction, Auger electron spectroscopy, microprobe analysis, electron microscopy, infrared spectroscopy, and $\mathrm{x}$-ray photoelectron spectroscopy.

\subsection{Calibration Requirements}

Calibration of the TGA apparatus and associated hardware will be performed by the users according to the TIPs specified in "Technical Implementing Procedures" (Section 8.0). These calibrations will be documented in the scientific notebook.

The surface analytical work will be performed by personnel who will be indoctrinated to the Yucca Mountain Project. Calibrations for the analytical equipment will be documented in the scientific notebook.

4.2 Conditions which may adversely affect results

Conditions which may adversely affect the test results are uncontrolled fluctuations in humidity, temperature, and specimen weight. Equipment modifications to the commercial TGA apparatus to control these fluctuation are described in "Equipment" (Section 3.3).

\subsection{Sources of uncertainty and error to be controlled and measured}

Any test measurement from a single specimen of a specific alloy may give anomalous results, therefore multiple specimens of a specified alloy will be used to ensure consistency. 


\subsection{Standards}

The standards to be followed or used for guidance are listed below.

ASTM G 46-94, "Guide for Examination and Evaluation of Pitting Corrosion"

ASTM G 1-90, "Practice for Preparing, Cleaning, and Evaluating Corrosion Test Specimens"

ASTM G 50-76 (1992), "Practicc for Conducting Atmospheric Corrosion Tests on Metals"

\subsection{IN-PROCESS DOCUMENTATION}

Documentation to be generated during the conduct of this activity will include scientific notebooks and may also include data record sheets, raw data, progress reports and the final report. Scientific notebooks are controlled and maintained in accordance with procedure 033-YMP-QP 3.4, "Scientific Notebooks." Test specimens will be controlled and maintained in accordance with procedure 033-YMP-QP 8.0, "Identification and Control of Items, Samples, and Data." The extent of detail in the documentation will insurc that the tests will be repeatable in principle

After completion of the activity, a LLNL UCID report will be written. Interim LLNL UCID reports may also be written if deemed appropriate. The report(s) will undergo technical review as specified in procedure 033-YMP-QP-3.3, "Review of Technical Publications and Data."

\subsection{Data Recording and Data Reduction}

Specimen weight changes as a function of time are recorded by the PC connected to the CAHN TG-131 apparatus. Reaction vessel temperature, air flow rates, and relative humidity measurements from the Relative Humidity / Temperature (RTD) Sensor (HYCAL Model CT-890-AN) are recorded by a Fluke Hydra Data Bucket. The data from the Data Bucket is transferred to the PC and combined with the weight change data into a single data file in an appropriate spreadsheet. The 
filename of the data is entered in the scientific notebook and referenced to the test run number.

Data recording, reduction, and analysis will be done through the use of scientific notebooks, data record sheets, and working spreadsheets.

\subsection{Analysis}

Analysis of the data will include evaluation of the critical relative humidity as a function of metal alloy, temperature, gas composition, and surface condition. Where appropriate kinetic and mechanistic analysis of test data will be performed. Analysis will be recorded in the scientific notébook.

\subsection{INTERFACES}

The information obtained in this activity will assist activities in the following technical areas:

1) Metal Barrier Selection and Testing (SIP-CM-01)

R.D. McCright, TAL, Metal Barrier Selection and Testing

2) Waste Package Performance Assessment activities (SIP-PA-2) W. Halsey, TAL, Performance Assessment

After initiation of the experimental work of this activity, the monthly progress reports from this activity will be sent to TALs identified with the above SIP and activitics. If deemed appropriate, meetings of cognizant PIs to discuss the activity's results will be arranged.

\subsection{SCHEDULE}

The TGA scoping studies and equipment modification of the TGA are expected to be completed by August of FY95. Testing with candidate materials will commence thereafter and is expected to be completed in FY96. 


\subsection{TECHNICAL IMPLEMENTING PROCEDURES}

The Technical Implementing Procedures (TIPs) that are planned for the performance of this activity cover the following topics (tentative titles):

1) "Calibration of TGA Microbalance"

2) "Calibration of Humidity and Temperature Sensor"

3) "Testing Procedure for the Thermogravimetric Analyzer"

\subsection{SOFTWARE}

The commercial software that will be utilized in the Thermogravimetric Analysis Studies are:

TGA Setup and Analysis (ATI/Mattson), the control program for the CAHN TG131

Igor (Wavemetrics) or similar programs for graphing and data analysis.

Excel (Microsoft) or similar spreadsheet and graphing programs for displaying ICF control and process parameters on a monitor.

Fluke TrendLink and HydraLogger; controls and plots data from Fluke Data Bucket.

Any software that will be used for analysis of the test data will be identified in the activity's Scientific Notebook.

\subsection{SPECIAL CASES}

No subcontractors are involved in this activity.

\subsection{REFERENCES}

There are no references. 


\subsection{APPENDIX}

There are no appendices. 
Table 1. Compositions of Candidate Container Materials.

\begin{tabular}{|c|c|c|c|}
\hline UNS number & $\begin{array}{l}\text { Common or Commercial } \\
\text { Name }\end{array}$ & ASTM Number & Nominal Composition (weight \%) \\
\hline N08825 & $\begin{array}{l}\text { Alloy } 825 \\
\text { Incoloy } 825\end{array}$ & B 424 (plate) & $\begin{array}{l}\text { Ni } 38.0-46.0 ; \text { Cr } 19.5-23.5 ; \text { Mo } 2.5- \\
\text { 3.5; Fe balance; Cu 1.5-3.0; Ti 0.6- } \\
\text { 1.2; Mn } 1.0 \text { max; C } 0.05 \max \text {; Si } 0.5 \\
\max \text {; S } 0.03 \text { max; Al } 0.2 \max \end{array}$ \\
\hline N06985 & $\begin{array}{l}\text { Alloy G-3, } \\
\text { Hastelloy G-3 }\end{array}$ & B 582 (plate) & $\begin{array}{l}\text { Ni balance; Cr 21.0-23.5; Mo 6.0-8.0; } \\
\text { Fe 18.0-21.0; W } 1.5 \mathrm{max} \text {; Co 5.0; Cu } \\
\text { 1.5-2.5; Nb+Ta 0.5 max; Mn } 1.0 \mathrm{max} \text {; } \\
\text { C 0.15 max; Si } 1.0 \mathrm{max} \text { S } 0.03 \mathrm{max} \\
\text { P 0.04 max }\end{array}$ \\
\hline N06455 & $\begin{array}{l}\text { Alloy C-4, } \\
\text { Hastelloy C-4 }\end{array}$ & B 575 (plate) & $\begin{array}{l}\text { Ni balance; Cr } 14.0-18.0 ; \text { Mo } 14.0- \\
17.0 ; \text { Fe } 3.0 \max \text {; Co } 2.0 \max \text {; Mn } 1.0 \\
\max \text { C C } 0.015 \max ; \text { Si } 0.8 \max \text {; Ti } 0.7 \\
\max ; \text { S.0.03 } \max ; \text { P } 0.04 \max \end{array}$ \\
\hline N06022 & $\begin{array}{l}\text { Alloy C-22, } \\
\text { Hastelloy C-22 }\end{array}$ & B 575 (plate) & $\begin{array}{l}\text { Ni balance; Cr 20.0-22.0; Mo } 12.5- \\
14.5 ; \mathrm{Fe} 2.0-6.0 ; \mathrm{W} 2.5-3.5 ; \mathrm{Co} 2.5 \\
\max \text {; Mn 0.5 max; C } 0.015 \max ; \mathrm{Si} \\
0.8 \max ; \text { V0.35 max; S } 0.02 \text { max; } \mathrm{P} \\
0.02 \max \end{array}$ \\
\hline R53400 & Ti-Grade 12 & B 265 Grade 12 & $\begin{array}{l}\text { Ni } 0.6-0.9 ; \text { Mo } 0.2-0.4 ; \text { N } 0.03 \max \\
\text { C } 0.08 \text { max; H } 0.015 \text { max; Fe } 0.3 \\
\text { max; O } 0.25 \text { max; Ti balance }\end{array}$ \\
\hline none to date & Ti-Grade 16 & none to date & $0.05 \mathrm{Pd} ; 0.1 \mathrm{Ru} ;$ Ti balance \\
\hline
\end{tabular}


N04400

C71500

K01800

J02501

$\vec{\sigma}$

K21590
Alloy 400 ,

Monel 400

B 127 (plate)

70-30 copper-nickel,

CDA 715

B 171 (plate)

1020 Carbon Steel

A 516 (Grade 55)

Centrifugally Cast Steel

$2.25 \mathrm{Cr}$ - 1Mo Alloy Steel
A 27 (Grade 70-40)

A 387 (Grade 22)
Ni 63.0 min; Cu 28.0-34.0; Fe 2.5 max; Mn 2.0 max; C 0.03 max; Si 0.5 $\max$; Si $0.5 \max ;$ S $0.024 \max$

Ni 29.0-33.0; Cu balance; $\mathrm{Mn} 1.0$ $\max$; Pb 0.02 max; Fe 0.4-1.0; Zn 0.5 max; C 0.05 max; P 0.02 max; S 0.02 $\max$

C 0.22 max; Mn 0.6-1.2; P 0.035 max; S 0.04 max; Si 0.15-0.40; Fe remainder

C 0.25 max; Mn 1.2 max; P 0.050 max; S 0.060 max; Si 0.80 max; Fe remainder

C 0.15 max; Mn 0.3-0.6; P 0.035 $\max$; $\mathrm{S} 0.035$ max; Si $0.5 \max ; \mathrm{Cr}$ 2.00-2.50; Mo 0.90-1.10; Fe remainđer 


\section{Thermogravimetric Analyzer Apparatus}



